\title{
PSEUDO-ALMOST AUTOMORPHIC SOLUTIONS TO SOME CLASSES OF NONAUTONOMOUS PARTIAL EVOLUTION EQUATIONS
}

\author{
TOKA DIAGANA
}

Abstract. In this paper we obtain the existence of pseudo-almost automorphic solutions to some classes of nonautonomous partial evolution equations. To illustrate our main result, we study the existence of a pseudo-almost automorphic solution to a nonautonomous heat equation.

Mathematics subject classification (2000): 43A60, 34B05, 34C27, 42A75, 47D06, 35L90.

Keywords and phrases: sectorial operator, evolution family, exponential dichotomy, hyperbolic evolution family, Acquistapace and Terreni conditions, almost automorphic, pseudo-almost automorphic, hyperbolic evolution equation, nonautonomous equation, heat equation in divergence.

\section{REFERENCES}

[1] P. ACQUISTAPACE, Evolution operators and strong solutions of abstract linear parabolic equations, Differential Integral Equations, 1 (1988), 433-457.

[2] P. ACQUistapaCe, F. Flandoli, B. TERREni, Initial boundary value problems and optimal control for nonautonomous parabolic systems, SIAM J. Control Optim., 29 (1991), 89-118.

[3] P. ACQUistAPACE, B. TERRENI, A unified approach to abstract linear nonautonomous parabolic equations, Rend. Sem. Mat. Univ. Padova, 78 (1987), 47-107.

[4] H. Amann, Linear and Quasilinear Parabolic Problems, Birkhäuser, Berlin 1995.

[5] B. AMIR AND L. MANIAR, Existence and some asymptotic behaviors of solutions to semilinear Cauchy problems with non dense domain via extrapolation spaces, Rend. Circ. Mat. Palermo II, 49 (2000), 481-496.

[6] B. AMIR AND L. MAniar, Composition of pseudo-almost periodic functions and cauchy problems with perator of nondense domain, Ann. Math. Blaise Pascal, 6, 1 (1999), 1-11.

[7] M. Baroun, S. Boulite, T. Diagana, And L. Maniar, Almost periodic solutions to some semilinear non-autonomous thermoelastic plate equations, J. Math. Anal. Appl., 349, 1 (2009), 74-84.

[8] M. Baroun, S. Boulite, G. M. N'GuÉrÉKATA, And L. ManiAR, Almost automorphy of semilinear parabolic equations, Electron. J. Differential Equations, 2008, 60 (2008), 1-9.

[9] S. Boulite, L. MAniar, And G. M. N'GuÉREKATA, Almost automorphic solutions for hyperbolic semilniear evolution equations, Semigroup Forum, 71 (2005), 231-240.

[10] D. BugAJEWS Ki AND T. DiaganA, Almost automorphy of the convolution operator and applications to differential and functional-differential equations, Nonlinear Stud., 13, 2 (2006), 129-140.

[11] D. Bugajewsi, T. Diagana, C. M. Mahop, Asymptotic and pseudo almost periodicity of the convolution operator and applications to differential and integral equations, Z. Anal. Anwend., 25, 3 (2006), 327-340.

[12] P. CiEUTAT AND K. EZZINBI, Existence, uniqueness and attractiveness of a pseudo almost automorphic solutions for some dissipative differential equations in Banach spaces, J. Math. Anal. Appl., 354, 2 (2009), 494-506.

[13] G. Da Prato And P. GRIs VARD, Equations d'évolution abstraites non linéaires de type parabolique, Ann. Mat. Pura Appl., 120, 4 (1979), 329-396.

[14] T. DiAgAnA, Existence of pseudo-almost automorphic solutions to some abstract differential equations with $\mathbb{S}^{p}$-pseudo-almost automorphic coefficients, Nonlinear Anal., 70, 11 (2009), 3781-3790.

[15] T. Diagana, Pseudo almost periodic functions in Banach spaces, Nova Science Publishers, Inc., New York, 2007. 
[16] T. DiAgAnA AND E. HERnÀndEZ, Existence and uniqueness of pseudo almost periodic solutions to some abstract partial neutral functional-differential equations and applications, J. Math. Anal. Appl., 327, 2 (2007), 776-791.

[17] T. Diagana, Existence and uniqueness of pseudo almost periodic solutions to some classes of partial evolution equations, Nonlinear Anal., 66, 2 (2007), 384-395.

[18] T. Diagana And G. M. N'GuÉRÉKATA, Pseudo almost periodic mild solutions to hyperbolic evolution equationa in abstract intermediate Banach spaces, Applicable Anal., 85, 6-7 (2006), 769-780.

[19] T. Diagana, N. HenríqueZ, And E. Hernàndez, Almost automorphic mild solutions to some partial neutral functional-differential Equations and Applications, Nonlinear Anal., 69, 5 (2008), $1485-1493$.

[20] T. Diagana And G. M. N'GuÉRÉKATA, Almost automorphic solutions to some classes of partial evolution equations, Appl. Math. Lett., 20, 4 (2007), 462-466.

[21] K. J. Engel AND R. NAGEL, One parameter semigroups for linear evolution equations, Graduate texts in Mathematics, Springer Verlag 1999.

[22] K. EzZinbi, S. Fatajou And G. M. NGuÉRÉKATA, Pseudo almost automorphic solutions to some neutral partial functional differential equations in Banach space, Nonlinear Anal., 70, 4 (2009), 16411647.

[23] K. Ezzinbi, S. Fatajou And G. M. NGuÉréKata, Pseudo almost automorphic solutions for dissipative differential equations in Banach spaces, J. Math. Anal. Appl., 351, 2 (2009), 765-772.

[24] A. M. FINK, Almost Periodic Differential Equations, Lecture Notes in Mathematics, 377, SpringerVerlag, New York-Berlin, 1974.

[25] E. HERNÁNDEZ AND H. R. HENRÍQUEZ, Existence of periodic solutions of partial neutral functional differential equations with unbounded delay, J. Math. Anal. Appl., 221, 2 (1998), 499-522.

[26] E. HERNÁNDEZ, Existence Results for Partial Neutral Integro-differential Equations with Unbounded Delay, J. Math. Anal. Appl., 292, 1 (2004), 194-210.

[27] E. Hernández M., M. L. Pelicer, And J. P. C. Dos Santos, Asymptotically almost periodic and almost periodic solutions for a class of evolution equations, Electron. J. Diff. Eqns., 2004, 61 (2004), 1-15.

[28] Y. Hino, T. Naito, N. V. Minh, And J. S. Shin, Almost Periodic Solutions of Differential Equations in Banach Spaces, Stability and Control: Theory, Methods and Applications, 15, Taylor and Francis, London, 2002.

[29] J.-L. Lions And J. Peetre, Sur une classe d'espaces d'interpolation, Inst. Hautes tudes Sci. Publ. Math., 19 (1964), 5-68.

[30] A. LunARDi, Analytic Semigroups and Optimal Regularity in Parabolic Problems, PNLDE, 16, Birkhäauser Verlag, Basel, 1995.

[31] J. LIANG, J. ZHANG, AND T-J. XIAO, Composition of pseudo almost automorphic and asymptotically almost automorphic functions, J. Math. Anal. Appl., 340 (2008), 1493-1499.

[32] J. LiAng, G. M. N'GuérékATA, T-J. XiAO, AND J. Zhang, Some properties of pseudo almost automorphic functions and applications to abstract differential equations, Nonlinear Anal., 70, 7 (2009), 2731-2735.

[33] L. MANiAR AND R. Schnaubelt, Almost periodicity of inhomogeneous parabolic evolution equations, Lecture Notes in Pure and Appl. Math., 234, Dekker, New York (2003), 299-318.

[34] M. G. NASO And A. Benabdallah, Thermoelastic plate with thermal interior control, Mathematical models and methods for smart materials (Cortona, 2001), 247-250, Ser. Adv. Math. Appl. Sci., 62, World Sci. Publ., River Edge, NJ, 2002.

[35] G. M. N'GUÉRÉKATA, Almost automorphic functions and almost periodic functions in abstract spaces, Kluwer Academic / Plenum Publishers, New York-London-Moscow, 2001.

[36] G. M. N'GUÉRÉKATA, Topics in almost automorphy, Springer, New york, Boston, Dordrecht, Lodon, Moscow 2005.

[37] G. M. N'GuÉRÉKATA AND A. PANKov, Stepanov-like almost automorphic functions and monotone evolution equations, Nonlinear Anal., 68, 9 (2008), 2658-2667.

[38] A. PAZY, Semigroups of linear operators and applications to partial differential equations, Applied Mathematical Sciences, 44. Springer-Verlag, New York, 1983.

[39] J. PRÜSS, Evolutionary Integral Equations and Applications, Birkhäuser, 1993.

[40] R. SCHNAUBELT, Sufficient conditions for exponential stability and dichotomy of evolution equations, Forum Math., 11 (1999), 543-566. 
[41] R. Schnaubelt, Asymptotically autonomous parabolic evolution equations, J. Evol. Equ., 1 (2001), $19-37$.

[42] R. Schnaubelt, Asymptotic behavior of parabolic nonautonomous evolution equations, in: M. Iannelli, R. Nagel, S. Piazzera (Eds.), Functional Analytic Methods for Evolution Equations, in: Lecture Notes in Math., 1855, Springer-Verlag, Berlin, 2004, 401-472.

[43] T-J. Xiao, J. Liang, J. Zhang, Pseudo almost automorphic solutions to semilinear differential equations in Banach spaces, Semigroup Forum, 76, 3 (2008), 518-524.

[44] Ti-J. XiaO, X-X. ZHU, J. Liang, Pseudo-almost automorphic mild solutions to nonautonomous differential equations and applications, Nonlinear Anal., 70, 11 (2009), 4079-4085.

[45] A. YAGI, Parabolic equations in which the coefficients are generators of infinitely differentiable semigroups II, Funkcial. Ekvac., 33 (1990), 139-150.

[46] A. YAGI, Abstract quasilinear evolution equations of parabolic type in Banach spaces, Boll. Un. Mat. Ital. B (7), 5 (1991), 341-368.

[47] S. Zaidman, Topics in Abstract Differential Equations, Pitman Research Notes in Mathematics Ser. II John Wiley and Sons, New York, 1994/1995. 